\title{
The effects of water-fertilizer integration on productivity of winter wheat and water-fertilizer utilizing efficiency under irrigation based on testing soil moisture
}

\author{
Xiaoshuang $\mathrm{Li}^{2}$, Chunlian Zheng ${ }^{1}$, Caiyun $\mathrm{Cao}^{1}$, Junyong $\mathrm{Ma}^{1}$, Kejiang $\mathrm{Li}^{1}$ and Hongkai Dang ${ }^{1, *}$ \\ ${ }^{1}$ Dryland Farming Institute, Hebei Acadamy of Agricultural and Forestry Sciences, Hengshui, China \\ ${ }^{2}$ Farmland Irrigation Research Institute, Chinese Academy of Agricultural Sciences, Xinxiang, China
}

\begin{abstract}
In order to explore efficient technic of water-fertilizer irrigation of wheat and provide theoretical support for wheat farming, this research investigate the effects of micro sprinkling irrigation with $180 \mathrm{~cm}$ width on distribution of moisture and nutrient in soil, water and fertilizer consumption, and grain yield of winter wheat. Field test was carried out during growth season of wheat, Water-saving wheat variety "Heng4399" was used as test material. Four times of irrigation were implemented in Spring. Combining with soil moisture criterion during reproduction period, soil moisture was tested before each time of irrigation, and the sprinkling irrigation was initiated if drought appeared. The bands of sprinkler were set in between, and parallel to lines of wheat, with irrigation width of $1.8 \mathrm{~m}$, covering 6 lines of wheat (L1-L6) on each side of band. The experiment showed that wheat production reached to $7844.9-8194.8 \mathrm{~kg} / \mathrm{hm}^{2}$, with no significant difference among the lines of wheat. The maximum accumulation of $\mathrm{N}$ and $\mathrm{P}_{2} \mathrm{O}_{5}$ appeared during maturity and reached to $260.25-295.95 \mathrm{~kg} / \mathrm{hm}^{2}$ and $109.89-139.61 \mathrm{~kg} / \mathrm{hm}^{2}$, respectively. The maximum accumulation of $\mathrm{K}_{2} \mathrm{O}$ was $251.35-297.29 \mathrm{~kg} / \mathrm{hm}^{2}$ during anthesis stage. The difference of $\mathrm{K}_{2} \mathrm{O}$ accumulation among wheat lines was significant. The distribution of nutrients in each organ of wheat was irregular. These results suggested that the width of sprinkling irrigation had no significant effect on nutrient assimilation and productivity of wheat. Soil moisture was positively correlated to rapidly available phosphorus content before anthesis and alkali-hydrolysable nitrogen content in each layer of soil, and was negatively correlated to rapidly available potassium in late seed filling stage. Based on the results, we suggest that applying nitrogen fertilizer multiple times at different stages. Phosphorus fertilizer can be implemented at early reproduction stage based on nutrient demand of wheat. All potassium fertilizer is recommended to be applied as base manure.
\end{abstract}

\section{Introduction}

Sprinkling irrigation is an efficient irrigating technic with many advantages, such as conserving water, increasing productivity, saving space and less labor requirement [1]. It is an important, wide-spreading modern irrigating method to regulate growth conditions of crops [2]. Sprinkling irrigation keeps moisture in soil and supplies water to crops by simulating rainfall. Due to the effects of water pressure and spacing between irrigation bands, irrigating homogeneity significantly influence outcome of irrigation. Since wheat is high-density crop, it is normally farmed with $15 \mathrm{~cm}$ line spacing in Hebei Plain [3]. Therefore, during late reproduction stage, water flow is blocked by dense stalks of wheat, reducing irrigating homogeneity. Sprinkling irrigation can also achieve water-fertilizer integration with pressure system. Based on these properties, distribution of moisture and fertilizer in soil under sprinkling irrigation is obviously different from that under natural rainfall and surface irrigation [2]. Previous research has already studied the effects of sprinkling irrigation on the utilization of water and fertilizer and growth of wheat. Lv et al. [4] pointed out that sprinkling irrigation increased light interception and leaf area index of wheat and promoted accumulation of dry matter at middle/late stages. Yao et al. [2] suggested sprinkling irrigation increased 1000-grain weight of wheat. Dang et al. [5] showed that compared to traditional flood irrigation, sprinkling irrigation more accurately controlled amount of water and increased water utilizing efficiency. Yu et al. [6] showed wheat yield had quadratic function correlation with water utilizing efficiency and water consumption. However, under sprinkling irrigation and fertilization, the relation among different spacing between sprinkling bands, water and fertilizer transporting traits of soil, dry matter accumulation of wheat and pattern of nutrient assimilation still need further study.

\footnotetext{
* Corresponding author: wheatcrop@126.com
} 
Hebei province is one of the most important provinces producing wheat, limited by conflict of water requirement of wheat and water shortage in the area [7]. Efficient water utilization can be achieved by irrigating with limitation and water fertilizer coupling during critical stages of wheat growth. It has been widely studied how to keep water and nutrient supplement for wheat by irrigation of multiple times with small amount of water and water-fertilizer integration under sprinkling irrigation [8]. But studies about influence of soil moisture and nutrient transportation on nutrient assimilation, community structure and productivity of wheat in Hebei low plain area are still needed. In this experiment, by analyzing difference of water and fertilizer transportation and nutrient assimilation at various distance with $1.8 \mathrm{~m}$ sprinkling band, properties of wheat community and individuals at various distance, at different growth stages were elucidated.

\section{Materials and methods}

\subsection{Background information of the field}

The field test was carried out in Wuqiang County, Hebei Province. Wuqiang is a county located in south central of the province in Heilonggang Plain, a typical semi-arid area in northern China, with altitude of $19 \mathrm{~m}$. The average participation during wheat growth season was $109 \mathrm{~mm}$ and annual average temperature was $12.0{ }^{\circ} \mathrm{C}$. Underground water was below $10 \mathrm{~m}$ depth. Soil in the testing field was fluvo-aquic soil. The remains of summer crops from previous farming was buried in the field. The soil basic fertility of $0-20 \mathrm{~cm}$ layer of the field was: $14.71-15.63 \mathrm{~g} / \mathrm{kg}$ organic matter, $0.65-0.71 \mathrm{~g} / \mathrm{kg}$ total nitrogen, $87.9-105.4 \mathrm{mg} / \mathrm{kg}$ alkali-hydrolysable nitrogen, $15.7-16.2 \mathrm{mg} / \mathrm{kg}$ rapidly available phosphorus, $84.3-102.6 \mathrm{mg} / \mathrm{kg}$ rapidly available potassium. Bulk density of $0-100 \mathrm{~cm}$ soil was $1.52 \mathrm{~g} / \mathrm{cm}^{3}$. Field water holding capacity was $34.96 \%$ and moisture before sowing was $34.26 \%$. The species of wheat for testing was water-saving, high-yield winter wheat, Heng4399. The wheat was sowed at 10th of October, with ling spacing of $15 \mathrm{~cm} .40 \mathrm{~kg} / \mathrm{mu}$ complex fertilizer (19-21-5) was applied as base fertilization, followed by $30 \mathrm{~kg} / \mathrm{mu}$ water-soluble fertilizer. The total amount of fertilizers was: approximately $253.5 \mathrm{~kg}$ of total nitrogen, $162 \mathrm{~kg}$ total phosphorus and $84 \mathrm{~kg} / \mathrm{mu}$ total potassium.

The field was 10 hectares, tested by tracking survey. The field was subject to consistent and unified administration for years, therefore, soil fertility was homogenous. The first sprinkling band was set at $0.9 \mathrm{~m}$ from one edge of the field. Sprinkling bands were $45 \mathrm{~m}$ long, with irrigating width of $1.8 \mathrm{~m}$. Half perimeter of sprinkling band was $65 \mathrm{~mm}$. Diameter of sprinkling hole was $0.5 \mathrm{~mm}$. Interval between two holed was $25 \mathrm{~mm}$. Each group had 5 holes, with arrangement of arc, and intervals of $18 \mathrm{~cm}$. Working pressure inside sprinkling band was $0.3 \mathrm{Mpa}$. Irrigating intensity was $30 \mathrm{~mm} / \mathrm{h}$.

Table 1. shows dynamics of number of stalks in different stages and grain yield during maturity.

\begin{tabular}{|c|c|c|c|c|c|c|c|c|c|}
\hline \multirow[b]{2}{*}{ Treatments } & \multicolumn{4}{|c|}{ Population dynamic $\left(10^{4} \cdot\right.$ plant $\left./ \mathrm{hm}^{2}\right)$} & \multicolumn{5}{|c|}{ productivity } \\
\hline & Jointing & Heading & Anthesis & Filling & $\begin{array}{l}\text { Height } \\
(\mathrm{cm})\end{array}$ & Grain number per spike & $\begin{array}{c}\text { 1000-grain weight } \\
\text { (g) }\end{array}$ & $\begin{array}{c}\text { Yield } \\
\left(\mathrm{kg} / \mathrm{hm}^{2}\right)\end{array}$ & $\begin{array}{c}\text { Economical index } \\
(\%)\end{array}$ \\
\hline L1-L2 & $1065.0 \mathrm{a}$ & $811.7 \mathrm{a}$ & $723.5 \mathrm{a}$ & $695.1 \mathrm{a}$ & $71.1 \mathrm{a}$ & $34.7 \mathrm{a}$ & $31.78 \mathrm{a}$ & $8194.8 \mathrm{a}$ & $41.89 \mathrm{a}$ \\
\hline L3-L4 & $893.4 b$ & $758.4 \mathrm{a}$ & $715.1 \mathrm{a}$ & $706.8 \mathrm{a}$ & $70.5 \mathrm{a}$ & $32.5 \mathrm{a}$ & $31.71 \mathrm{a}$ & $8021.1 \mathrm{a}$ & $42.63 \mathrm{a}$ \\
\hline L5-L6 & $1021.7 \mathrm{a}$ & $791.7 \mathrm{a}$ & $733.4 \mathrm{a}$ & $660.0 \mathrm{~b}$ & $69.3 \mathrm{a}$ & $33.5 \mathrm{a}$ & $32.35 \mathrm{a}$ & $7844.9 \mathrm{a}$ & $43.37 \mathrm{a}$ \\
\hline
\end{tabular}

\subsection{Experimental design}

Four times of irrigation were implemented during jointing stage, heading stage, anthesis stage and filling stage, respectively. Soil moisture was tested before irrigation. When the moisture of testing layer was lower the critical level of drought, the irrigation was initiated. During jointing stage, heading stage, anthesis stage and filling stage, the testing layers were $0-60 \mathrm{~cm}, 0-60 \mathrm{~cm}, 0-80 \mathrm{~cm}$ and $0-80 \mathrm{~cm}$, and critical level of drought were $65 \%$, $70 \%, 75 \%$ and $70 \%$, respectively. The additional fertilization was $450 \mathrm{~kg} / \mathrm{hm} 2$. Intensity of irrigation was 135 $\mathrm{mm}$. The amount of irrigation and following fertilization in each stage were as followings: (1) jointing stage (7th April): $37.5 \mathrm{~mm}$ of irrigation, $180 \mathrm{~kg} / \mathrm{hm}^{2}$ of fertilization $\left(\mathrm{N}_{2} \mathrm{P}_{2} \mathrm{O}_{5}: \mathrm{K}_{2} \mathrm{O}=33: 6: 11\right)$. (2) heading stage (21st April): $37.5 \mathrm{~mm}$ of irrigation, $105 \mathrm{~kg} / \mathrm{hm}^{2}$ of fertilization $\left(\mathrm{N}: \mathrm{P}_{2} \mathrm{O}_{5}: \mathrm{K}_{2} \mathrm{O}=33: 6: 11\right)$. (3) anthesis stage (8th May): $30 \mathrm{~mm}$ of irrigation, $7 \mathrm{~kg} / \mathrm{hm}^{2}$ of fertilization $\left(\mathrm{N} \mathrm{P}_{2} \mathrm{O}_{5}: \mathrm{K}_{2} \mathrm{O}=27: 12: 14\right)$. (4) filling stage (18th May): $30 \mathrm{~mm}$ of irrigation, $45 \mathrm{~kg} / \mathrm{hm}^{2}$ of fertilization $\left(\mathrm{N}: \mathrm{P}_{2} \mathrm{O}_{5}: \mathrm{K}_{2} \mathrm{O}=27: 12: 14\right)$.

\subsection{Determining soil moisture and calculating field water consumption and water using efficiency.}

Samples were taken at 19-21m from top of each plot in double ridge stage (4th April), lengthen jointing stage 
(11st April), heading stage (23rd April), anthesis stage (5th May), filling stage (16th May) and maturity (13th June). 9 points were sampled between two sprinkling bands according to the distance from the bands $(0,30,60$, $90,60,30,0 \mathrm{~cm})$, divided into close $(0-30 \mathrm{~cm})$, medium $(30-60 \mathrm{~cm})$ and distant zone $(60-90 \mathrm{~cm})$, represented as L1-L2, L3-L4 and L5-L6. Weighted average was calculated for the sampling points in symmetry sampling area. Three replicates were taken among three joint sprinkling irrigation bands.

At each point, soil samples were obtained by drilling from 10 layers of field, $0-10 \mathrm{~cm}, 10-20 \mathrm{~cm}, 20-30 \mathrm{~cm}$, $30-40 \mathrm{~cm}, 40-50 \mathrm{~cm}, 50-60 \mathrm{~cm}, 60-70 \mathrm{~cm}, 70-80 \mathrm{~cm}, 80-90 \mathrm{~cm}$ and $90-100 \mathrm{~cm}$. Then, the samples were sealed in aluminum containers and the total weight of both sample and container was measured. After drying at $105^{\circ} \mathrm{C}$, the total weight was measured again and soil moisture was calculate. The water consumption of wheat was obtained according to the moisture with following equation [5]:

$$
E T_{1-2}=10 \sum_{i=1}^{n} \gamma_{i} H_{i}\left(\theta_{i 1}-\theta_{i 2}\right)+M+P_{0}+K
$$

Where $E T_{1-2}$ was stage water consumption; i represents soil layer; $n$ was number of soil layers; $\gamma_{i}$ was bulk density of layer $i ; H_{i}$ was thickness of layer $i ; \theta_{i 1}$ and $\theta_{i 2}$ were moisture of layer $i$ at the beginning and the end of each stage, respectively, and calculated as percentage of dry weight of soil; $M$ was amount of irrigation; $P_{0}$ was amount of effective participation; $K$ was supplement of underground water and assumed as 0 , because the underground water in this experiment was deeper than $2.5 \mathrm{~m}$.

\subsection{Measurements of nutrients in soil and wheat}

Soil samples left from moisture determination were gathered and naturally dried for measuring content of alkali-hydrolysable nitrogen, phosphorus and potassium. Nitrogen was measured by alkali-hydrolyzing nitrogen fixation and U2001 UV spectrophotometer. Rapidly available phosphorus was measured by sodium bicarbonate extraction and Mo-Sb Colorimetric Method. Potassium was extracted by ammonium acetate[9].

Five-point sampling and three replicates were applied for wheat in L1-L2, L3-L4 and L5-L6, in different growth stages. Each sample contain 30 seedling and 20 adults. Following manual observation check, each wheat individual was separated as leaves, stalk + leaf sheath + spike shell, and grains. The sample was treated by 105 ${ }^{\circ} \mathrm{C}$ for $30 \mathrm{~min}$ and then kept drying at $80^{\circ} \mathrm{C}$, then weighted, shattered and preserved.

The measurement of total nitrogen for wheat was performed by colorimetry with U2001 UV spectrophotometer. Total phosphorus was determined by V-Mo Yellow Colorimetric Method. Each organ was shattered and then digested by sulfuric acid-hydrogen peroxide. Potassium was measured by WGH-1A flame photometer[9].

\subsection{Data analysis}

Data processing and statistical analysis were performed by Excel and SPSS.

\section{Results and analysis}

\subsection{Effects of micro sprinkling irrigation on dynamics of water and nutrient in field}

\subsubsection{Nutrient dynamics in 0-100 cm soil at different growth stages}

Soil samples were taken after irrigation at heading stage (23rd April) and before irrigation at anthesis stage (5th May) and filling stage (16th May). Table 1 suggested that after irrigation, the dynamic of moisture in different layers was similar in each zone. There was no significant difference in moisture of 0-100 cm soil in L1-L2, L3-L4 and L5-L6 at each growth stage. The order of moisture of the three sampling zones was basically: L1-L2 $>$ L3-L4 $>$ I80-100. Further comparing soil layers at different stages, the deeper the soil was, the less moisture reduced. On 11th and 23rd April, no significant difference was observed in moisture in $60 \mathrm{~cm}$ or deeper soil. At anthesis stage (5th May), small difference existed in 0-20 cm soil, higher difference was observed in soil deeper than $20 \mathrm{~cm}$, and significant different appeared in soil deeper than $50 \mathrm{~cm}$. At filling stage (16th May), small 
difference in moisture was observed in soil layers, mostly in $20-40 \mathrm{~cm}$ soil. During maturity, the difference was least. Over all, the divergence of moisture was caused by inhomogeneity of sprinkling at early stages, by water absorption of wheat and sprinkling at middle stages, and extended to disappear during maturity.

The variation of alkali-hydrolysable nitrogen in soil layers at different stages was 25.4-121.31 ppm. Different from the distribution of water in soil, alkali-hydrolysable nitrogen was highest in $0-10 \mathrm{~cm}$, rapidly dropped in 10-20 cm, slowly declined in soil deeper than $20 \mathrm{~cm}$. The dynamics of alkali-hydrolysable nitrogen was similar as the pattern of moisture in each zone at different stages. The order of alkali-hydrolysable nitrogen content is:

L1-L2 $>$ L3-L4 $>$ I80-100. Comparing different layers at each stage, highest difference showed in 10-20 cm at heading stage (23rd April) and anthesis stage (5th April), in 0-10 cm during filling stage (16th May). At maturity stage, the difference in 0-30 cm was higher than that in 30-100 cm. In each zone, with the growth of wheat, the alkali-hydrolysable nitrogen declined in soil.

At different stages, the variation of nitrogen in soil was 4-46.98 ppm. Available phosphorus was highest in 0-10 $\mathrm{cm}$, declined rapidly in 10-20 cm, and appeared to be lowest in $20 \mathrm{~cm}$ or deeper. The divergence among these layers was irregular. Comparing different zones in each layer and each stage, the order of phosphorus content in soil was: L1-L2 > L3-L4>I80-100, except during heading stage, it was L3-L4>L1-L2 in 60-100 cm. Comparing different stages, phosphorus declined and reached the lowest at maturity stage, showing similar pattern as nitrogen.

The variation of potassium at different stages was 108.5-191.45 ppm. The distribution of the highest potassium was various at different stages. The highest potassium was detected in $0-10 \mathrm{~cm}$ at heading and filling stages, in $0-10 \mathrm{~cm}$ and $30-40 \mathrm{~cm}$ at anthesis stage, in 30-40 cm during maturity. The soil of 10-20 cm contained lowest potassium among all layers. In same layer and same stage, the order of potassium in different zones was: L1-L2

$>$ L3-L4 $>$ I80-100, except at heading stage, the potassium content was: I80-100 $>$ L1-L2 $>$ L3-L4 in 90-100 cm. With the passing of time, potassium decreased and was the lowest at maturity in $0-10 \mathrm{~cm}$ soil, and first declined and then dramatically increased during maturity in soil deeper than $10 \mathrm{~cm}$.
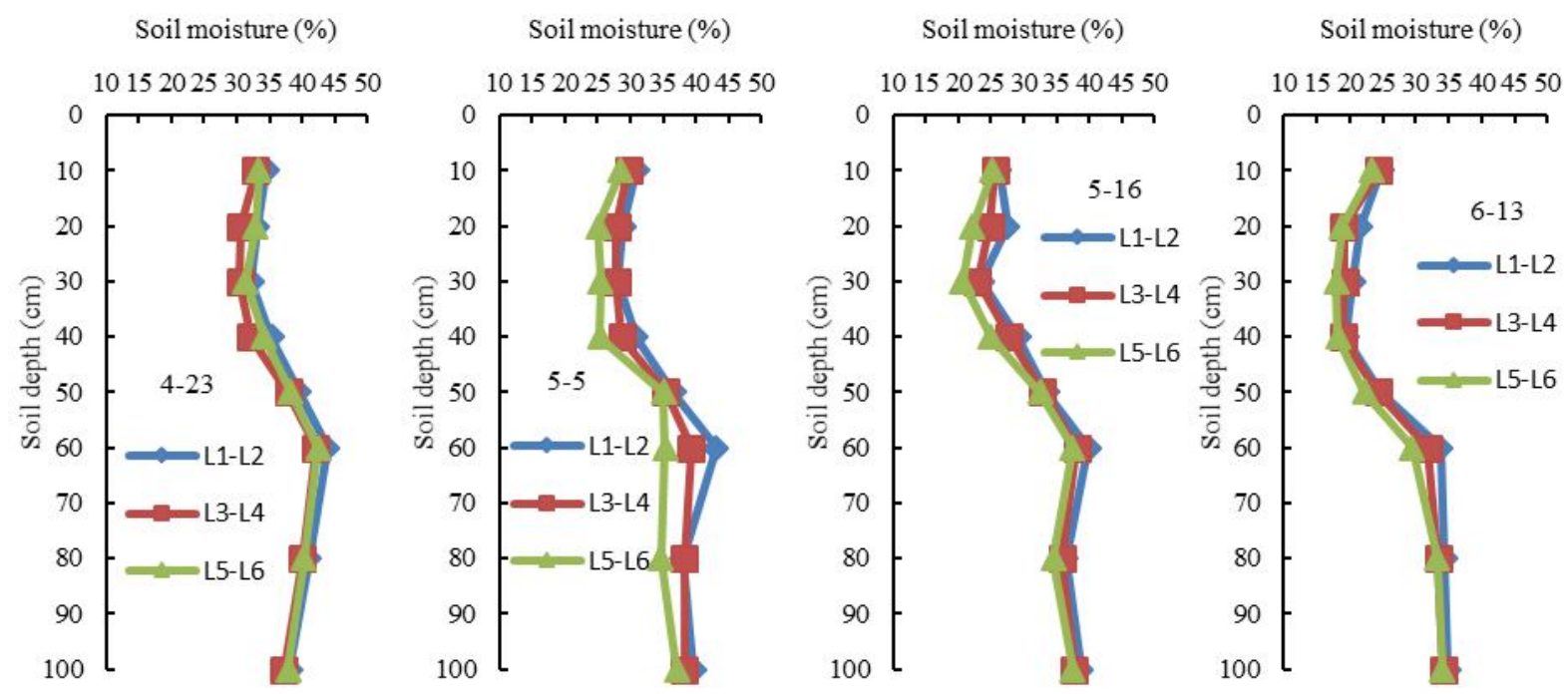


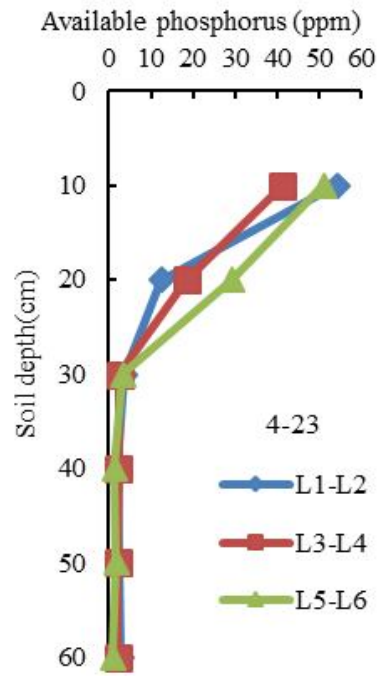

Available nitrogen (ppm) 20406080100120140

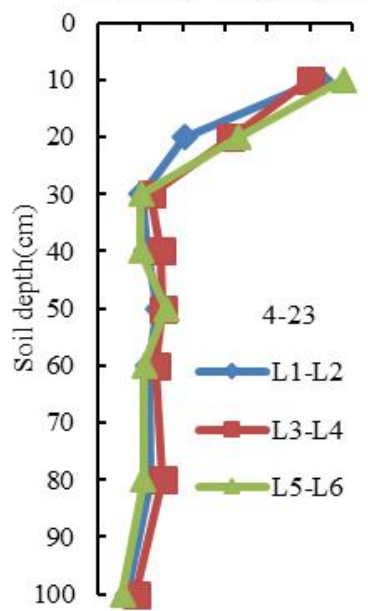

Available phosphorus (ppm) $\begin{array}{llllllll}0 & 10 & 20 & 30 & 40 & 50 & 60\end{array}$

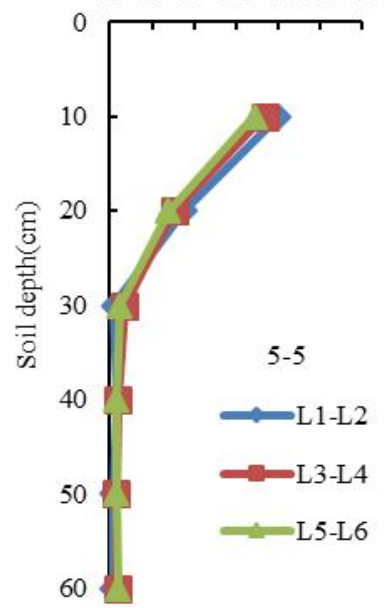

Available nitrogen (ppm) 20406080100120140

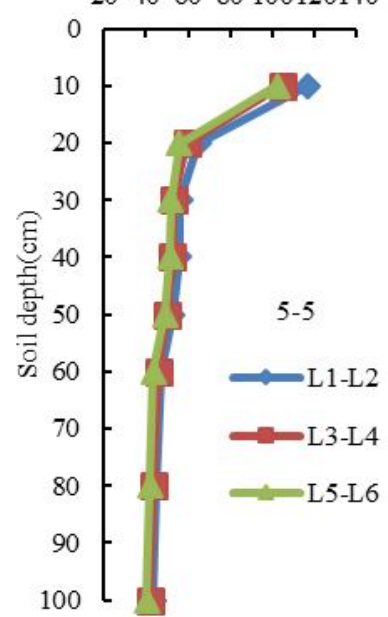

Available phosphorus (ppm) $0 \quad 1020 \quad 3040 \quad 5060$

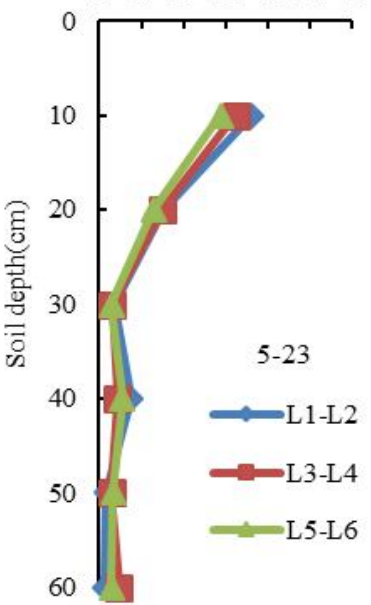

Available nitrogen (ppm)

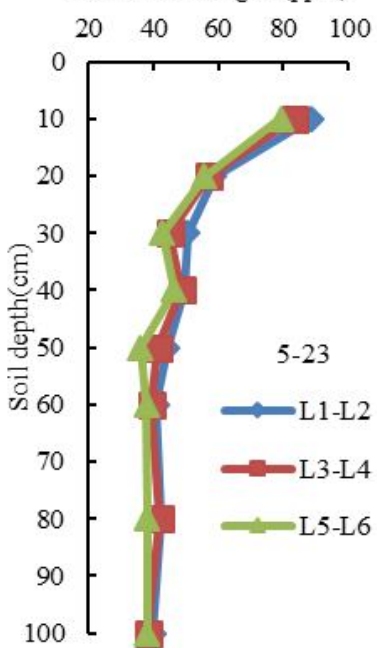

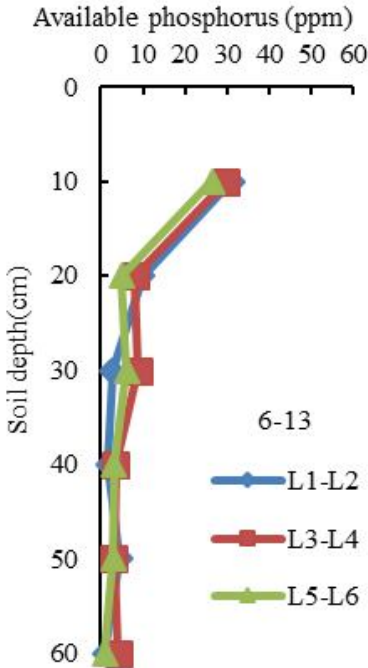

Available nitrogen (ppm)

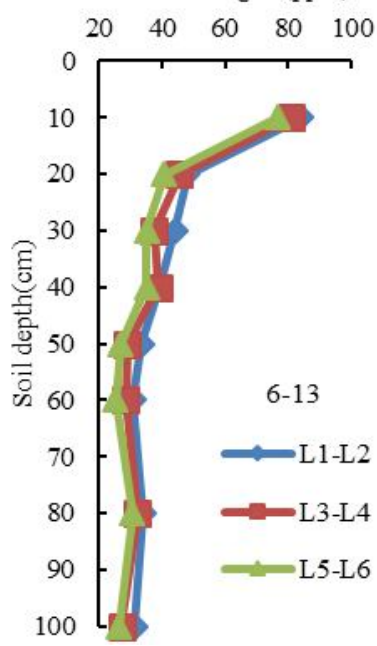

Fig. 1. Water and nutrient content in $0-100 \mathrm{~cm}$ soil of different treatments at different growth stages

\subsubsection{The correlation coefficient of nitrogen and water in 0-100 cm soil at different stages}

In Table 2, water variation positively correlated to nitrogen with the highest coefficient in L1-L2 from filling stage to maturity. The following coefficients in descending order were: nitrogen coefficient and phosphorus coefficient in L1-L2 from heading to anthesis stage, and coefficient for nitrogen in L3-L4 at the same stages. They all reached the significance of 0.05 . While, water variation and potassium were significantly negatively correlated in L1-L2 from filling stage to maturity. In general, moisture and nutrient consumption had positive correlation from heading to anthesis stage and negative correlation from anthesis to filling stage. From filling stage to maturity, correlation with nitrogen was positive, while correlation for phosphorus and potassium was negative. Moreover, the further from sprinkling band, the less corelated nutrient and water were, which indicated water and nutrient consumption was dependent.

Table 2. The correlation between moisture and nitrogen, phosphorus, and potassium

\begin{tabular}{|c|c|c|c|c|c|c|c|c|c|}
\hline \multirow{2}{*}{ Stages } & \multicolumn{3}{|c|}{$\mathrm{N}$} & \multicolumn{3}{|c|}{$\mathrm{P}_{2} \mathrm{O}_{5}$} & \multicolumn{3}{|c|}{$\mathrm{K}_{2} \mathrm{O}$} \\
\hline & L1-L2 & L3-L4 & L5-L6 & L1-L2 & L3-L4 & L5-L6 & L1-L2 & L3-L4 & L5-L6 \\
\hline Heading-anthesis & $0.7571^{*}$ & $0.7173 *$ & 0.5454 & $0.7514 *$ & 0.5852 & 0.2180 & 0.7024 & 0.6667 & 0.3734 \\
\hline Anthesis-filling & 0.6953 & 0.5424 & 0.4383 & 0.5263 & 0.2781 & 0.1480 & 0.1652 & -0.3601 & -0.4763 \\
\hline Filling-maturity & $0.7994 *$ & 0.6562 & 0.3682 & -0.5074 & -0.2428 & -0.1586 & $-0.8450^{* *}$ & -0.6518 & -0.1087 \\
\hline
\end{tabular}

\footnotetext{
* indicates significant correlation at the 0.05 level.
} 


\subsection{Effects of water-fertilizer integration on water consuming property of field}

\subsubsection{Effects of micro sprinkling on water supplement of soil}

In Table 3, we can see that from double ridge to lengthening stage, soil mostly stored water, the closer to sprinkling band, the more water accumulated. However, from lengthening to heading stage, the relation was opposite. After heading stage, soil mostly supplied water to wheat. From heading to anthesis stage, the closer to sprinkling band, the more water soil provided, while from anthesis stage to maturity, the relation also reversed. To summarize, the area with more water stored at early stages supplied more water later. The total water supplement of soil of different areas during entire growth of wheat was 129.62-155.47 mm. The water supplement of various areas was: I 80-100 $>$ I 40-80 $>$ I 0-40, in other words, further away from sprinkling band, more soil water consumed.

Table 3. Dynamics of water supply from soil during growth of winter wheat $(\mathrm{mm})$

\begin{tabular}{|c|c|c|c|c|c|c|c|}
\hline Treatments & Pre-sowing -Double ridge & Double ridge -Jointing & Jointing-heading & Heading-anthesis & Anthesis-filling & Filling-maturity & Total \\
\hline L1-L2 & $60.58 \pm 4.72 \mathrm{a}$ & $-57.53 \pm 3.79 c$ & $-2.99 \pm 0.06 \mathrm{a}$ & $29.38 \pm 3.20 \mathrm{~b}$ & $32.65 \pm 3.64 \mathrm{a}$ & $55.90 \pm 2.80 \mathrm{a}$ & $114.07 \pm 3.05 \mathrm{c}$ \\
\hline L3-L4 & $60.59 \pm 4.72 \mathrm{a}$ & $-42.07 \pm 4.61 b$ & $-8.94 \pm 0.12 b$ & $35.08 \pm 4.16 \mathrm{a}$ & $29.82 \pm 2.83 b$ & $54.89 \pm 2.32 \mathrm{a}$ & $125.79 \pm 4.12 b$ \\
\hline L5-L6 & $60.59 \pm 4.72 \mathrm{a}$ & $-23.93 \pm 4.90 \mathrm{a}$ & $-16.74 \pm 0.88 \mathrm{c}$ & $49.98 \pm 5.88 \mathrm{a}$ & $17.99 \pm 3.74 \mathrm{~b}$ & $51.08 \pm 5.07 \mathrm{a}$ & $136.81 \pm 4.95 \mathrm{a}$ \\
\hline
\end{tabular}

\subsubsection{Resource and ratio of field water consumption}

The field evaporation was $416.58 \mathrm{~mm}$ during growth of wheat in table 4 . Soil water was the first contributor for field evaporation, participation was the second, and irrigation was the last. The evaporation was highest in late stages of wheat growth, followed by the evaporation from sowing to lengthening stage. Unlike stage evaporation, stage day-average evaporation increased with the progress of growth.

Field evaporation variated in different times. It kept high level from sowing to jointing stage and from anthesis stage to maturity. Different from field evaporation, day-average evaporation increased along with the growth of wheat, reaching highest level of $5.50 \mathrm{~mm} / \mathrm{d}$ in middle-late filling stage.

Table 4. Resource and ratio of water consumption at different line spacing

\begin{tabular}{|c|c|c|c|c|c|c|c|c|c|}
\hline \multicolumn{6}{|c|}{ Stage variation } & \multicolumn{4}{|c|}{ Total variation } \\
\hline Pre-sowing-double ridge & Double ridge - jointing & Jointing -heading & Heading-anthesis & Anthesis-filling & Filling-maturity & Pre-sowing-double ridge & Double ridge - jointing & Jointing -heading & Heading-anthesis \\
\hline 164 & 7 & 12 & 12 & 11 & 27 & 164 & 171 & 183 & 195 \\
\hline 60.59 & -41.18 & -9.56 & 38.16 & 23.61 & 53.96 & 60.59 & 19.41 & 9.85 & 48.01 \\
\hline 0 & 37.5 & 37.5 & 0 & 30 & 30 & 0 & 37.5 & 75 & 75 \\
\hline 56.1 & 17.4 & 0 & 0 & 0.9 & 64.5 & 56.1 & 73.5 & 73.5 & 73.5 \\
\hline 116.69 & 13.72 & 27.94 & 38.16 & 54.51 & 148.46 & 116.69 & 130.41 & 158.35 & 196.51 \\
\hline 29.21 & 3.43 & 6.99 & 9.55 & 13.65 & 37.17 & 29.21 & 32.64 & 39.64 & 49.19 \\
\hline 0.71 & 1.96 & 2.33 & 3.18 & 4.96 & 5.50 & 0.71 & 0.76 & 0.87 & 1.01 \\
\hline
\end{tabular}

\subsection{Assimilation and distribution of $\mathrm{N}, \mathrm{P}_{2} \mathrm{O}_{5}$ and $\mathrm{K}_{2} \mathrm{O}$ in parts above ground}

\subsubsection{Dynamics of $\mathrm{N}, \mathrm{P}_{2} \mathrm{O}_{5}$ and $\mathrm{K}_{2} \mathrm{O}$ assimilation in wheat at various stages}

Table 5 showed that the variation of nitrogen in wheat was $1.44 \%-2.51 \%$. For $\mathrm{P}_{2} \mathrm{O}_{5}$ and $\mathrm{K}_{2} \mathrm{O}$, the variation was $0.61 \%-1.10 \%$ and $0.99 \%-2.70 \%$, respectively. During the growth of wheat, nitrogen content decreased while $\mathrm{P}_{2} \mathrm{O}_{5}$ and $\mathrm{K}_{2} \mathrm{O}$ content first increased and dropped later. The accumulation of nitrogen and $\mathrm{P}_{2} \mathrm{O}_{5}$ increased and reached highest value during maturity. The variation of highest nitrogen accumulation was $260.25-295.95 \mathrm{~kg} / \mathrm{hm}^{2}$. The variation of highest $\mathrm{P}_{2} \mathrm{O}_{5}$ accumulation was $109.89-139.61 \mathrm{~kg} / \mathrm{hm}^{2} . \mathrm{K}_{2} \mathrm{O}$ accumulation first increased to highest level in at anthesis stage and then decreased. The variation of the highest value was $251.35-297.29 \mathrm{~kg} / \mathrm{hm}^{2}$. 
Among different line spacing, nitrogen content and accumulation were both highest in L1-L2 at all stages. Compared to nitrogen, $\mathrm{P}_{2} \mathrm{O}_{5}$ and $\mathrm{K}_{2} \mathrm{O}$ were less affected by sprinkling. The order of content and accumulation of $\mathrm{N}_{2} \mathrm{P}_{2} \mathrm{O}_{5}$ and $\mathrm{K}_{2} \mathrm{O}$ in different zones was basically as: L1-L2 > L3-L4 > L5-L6.

Table 5. The content and accumulation of $\mathrm{N}, \mathrm{P}_{2} \mathrm{O}_{5}$ and $\mathrm{K}_{2} \mathrm{O}$ at different line spacing

\begin{tabular}{|c|c|c|c|c|c|c|c|}
\hline \multirow{2}{*}{ Stage } & \multirow{2}{*}{ Treatments } & \multicolumn{3}{|c|}{ Content $(\%)$} & \multicolumn{3}{|c|}{ Acccumulation $\left(\mathrm{kg} / \mathrm{hm}^{2}\right)$} \\
\hline & & $\mathrm{N}$ & $\mathrm{P}_{2} \mathrm{O}_{5}$ & $\mathrm{~K}_{2} \mathrm{O}$ & $\mathrm{N}$ & $\mathrm{P}_{2} \mathrm{O}_{5}$ & $\mathrm{~K}_{2} \mathrm{O}$ \\
\hline \multirow{3}{*}{ Jointing } & L1-L2 & $2.51 \pm 0.27 \mathrm{a}$ & $0.73 \pm 0.04 \mathrm{a}$ & $1.99 \pm 0.38 \mathrm{a}$ & $72.30 \pm 6.41 \mathrm{a}$ & $21.00 \pm 1.31 \mathrm{a}$ & $57.19 \pm 2.43 \mathrm{a}$ \\
\hline & L3-L4 & $2.21 \pm 0.36 \mathrm{ab}$ & $0.72 \pm 0.06 \mathrm{a}$ & $2.20 \pm 0.72 \mathrm{a}$ & $63.15 \pm 5.36 \mathrm{~b}$ & $20.55 \pm 2.23 \mathrm{a}$ & $62.73 \pm 3.61 \mathrm{a}$ \\
\hline & L5-L6 & $2.12 \pm 0.41 \mathrm{~b}$ & $0.82 \pm 0.04 \mathrm{a}$ & $1.99 \pm 0.44 \mathrm{a}$ & $49.20 \pm 3.82 \mathrm{c}$ & $19.05 \pm 2.56 \mathrm{a}$ & $45.94 \pm 4.02 \mathrm{~b}$ \\
\hline \multirow{3}{*}{ Anthesis } & L1-L2 & $2.19 \pm 0.02 \mathrm{a}$ & $1.10 \pm 0.03 \mathrm{a}$ & $2.70 \pm 0.09 \mathrm{a}$ & $234.15 \pm 3.31 \mathrm{a}$ & $117.70 \pm 2.31 \mathrm{a}$ & $287.90 \pm 11.04 \mathrm{a}$ \\
\hline & L3-L4 & $2.09 \pm 0.14 \mathrm{a}$ & $0.85 \pm 0.06 \mathrm{~b}$ & $2.55 \pm 0.14 \mathrm{a}$ & $243.75 \pm 2.62 \mathrm{a}$ & $99.30 \pm 5.52 \mathrm{~b}$ & $297.29 \pm 16.58 \mathrm{a}$ \\
\hline & L5-L6 & $2.11 \pm 0.36 \mathrm{a}$ & $0.89 \pm 0.032 \mathrm{~b}$ & $2.63 \pm 0.36 \mathrm{a}$ & $202.20 \pm 4.63 b$ & $85.35 \pm 6.76 \mathrm{c}$ & $251.35 \pm 16.76 \mathrm{~b}$ \\
\hline \multirow{3}{*}{ Maturity } & L1-L2 & $1.51 \pm 0.24 \mathrm{a}$ & $0.65 \pm 0.06 \mathrm{ab}$ & $0.99 \pm 0.13 \mathrm{a}$ & $295.95 \pm 8.73 \mathrm{a}$ & $127.58 \pm 7.64 \mathrm{a}$ & $193.24 \pm 12.46 \mathrm{a}$ \\
\hline & L3-L4 & $1.50 \pm 0.38 \mathrm{a}$ & $0.74 \pm 0.07 \mathrm{a}$ & $1.01 \pm 0.12 \mathrm{a}$ & $282.75 \pm 9.64 \mathrm{ab}$ & $139.61 \pm 8.85 \mathrm{a}$ & $190.61 \pm 16.83 a$ \\
\hline & L5-L6 & $1.44 \pm 0.06 \mathrm{a}$ & $0.61 \pm 0.00 \mathrm{~b}$ & $1.03 \pm 0.14 \mathrm{a}$ & $260.25 \pm 12.38 b$ & $109.89 \pm 10.96 \mathrm{~b}$ & $185.25 \pm 18.87 \mathrm{a}$ \\
\hline
\end{tabular}

\subsubsection{Distribution of $\mathrm{N}, \mathrm{P}_{2} \mathrm{O}_{5}$ and $\mathrm{K}_{2} \mathrm{O}$ in wheat}

At maturity stage, wheat organs contain $0.54 \%-2.55 \%$ of $\mathrm{N}, 0.41 \%-0.91 \%$ of $\mathrm{P}_{2} \mathrm{O}_{5}$ and $0.30 \%-1.75 \%$ of $\mathrm{K}_{2} \mathrm{O}$. The content of each nutrient was various in different organs. Grains contained highest $\mathrm{N}$ and $\mathrm{P}_{2} \mathrm{O}_{5}$ content, and stalks contained highest $\mathrm{K}_{2} \mathrm{O}$. N and $\mathrm{P}_{2} \mathrm{O}_{5}$ accumulated most in grains and account for $75.27 \%-78.67 \%$ and $59.70 \%-68.17 \%$ of entire plant, respectively. The percentage of $\mathrm{K}_{2} \mathrm{O}$ accumulation in stalks was $77.55 \%-78.34 \%$. The proportion of nutrient accumulation was similar as the proportion of nutrient content in weight in each organ, but not exactly the same. $\mathrm{N}$ accumulation was higher in stalks than in leaves, while the $\mathrm{N}$ content was the other way around. $\mathrm{K}_{2} \mathrm{O}$ accumulation was higher in grains than in leaves, while the $\mathrm{K}_{2} \mathrm{O}$ content was opposite.

The sprinkling bands affected the nutrient content and accumulation in different organs at maturity stage. The extent of the effects was as following order: L1-L2 $>$ L3-L4 $>$ L5-L6. The divergence in other organs was irregular.

Table 6. Distribution of $\mathrm{N}, \mathrm{P}_{2} \mathrm{O}_{5}$ and $\mathrm{K}_{2} \mathrm{O}$ in plant at maturity stage

\begin{tabular}{|c|c|c|c|c|c|c|c|c|c|c|}
\hline \multirow{2}{*}{ Organ } & \multirow{2}{*}{ Parameters } & \multicolumn{3}{|c|}{ Content $(\%)$} & \multicolumn{3}{|c|}{ Accumulation $\left(\mathrm{kg} / \mathrm{hm}^{2}\right)$} & \multicolumn{3}{|c|}{ Distribution (\%) } \\
\hline & & $\mathrm{N}$ & $\mathrm{P}_{2} \mathrm{O}_{5}$ & $\mathrm{~K}_{2} \mathrm{O}$ & $\mathrm{N}$ & $\mathrm{P}_{2} \mathrm{O}_{5}$ & $\mathrm{~K}_{2} \mathrm{O}$ & $\mathrm{N}$ & $\mathrm{P}_{2} \mathrm{O}_{5}$ & $\mathrm{~K}_{2} \mathrm{O}$ \\
\hline \multirow{3}{*}{ Leaves } & L1-L2 & $1.39 \pm 0.09 \mathrm{a}$ & $0.78 \pm 0.02 \mathrm{a}$ & $0.83 \pm 0.11 \mathrm{a}$ & $30.00 \pm 0.36 \mathrm{a}$ & $16.95 \pm 0.47 \mathrm{a}$ & $17.81 \pm 0.53 \mathrm{a}$ & $10.14 \pm 0.02 \mathrm{a}$ & $13.28 \pm 0.22 \mathrm{a}$ & $9.22 \pm 0.33 \mathrm{a}$ \\
\hline & L3-L4 & $1.16 \pm 0.13 \mathrm{a}$ & $0.76 \pm 0.10 \mathrm{a}$ & $0.79 \pm 0.16 \mathrm{ab}$ & $24.00 \pm 0.86 \mathrm{ab}$ & $15.75 \pm 1.18 \mathrm{ab}$ & $16.23 \pm 1.76 \mathrm{a}$ & $8.11 \pm 0.37 \mathrm{a}$ & $12.34 \pm 0.31 \mathrm{a}$ & $8.40 \pm 0.24 a$ \\
\hline & L5-L6 & $1.02 \pm 0.36 \mathrm{a}$ & $0.74 \pm 0.14 \mathrm{a}$ & $0.70 \pm 0.20 \mathrm{~b}$ & $20.40 \pm 1.21 \mathrm{~b}$ & $14.70 \pm 1.24 \mathrm{~b}$ & $13.88 \pm 1.93 b$ & $6.89 \pm 0.40 \mathrm{a}$ & $11.52 \pm 0.40 \mathrm{a}$ & $7.18 \pm 0.43 \mathrm{a}$ \\
\hline \multirow{3}{*}{ Stem } & L1-L2 & $0.75 \pm 0.07 \mathrm{a}$ & $0.41 \pm 0.00 \mathrm{~b}$ & $1.70 \pm 0.14 \mathrm{a}$ & $65.85 \pm 2.36 \mathrm{a}$ & $35.85 \pm 0.68 \mathrm{~b}$ & $149.25 \pm 0.86 \mathrm{a}$ & $23.29 \pm 0.19 \mathrm{a}$ & $25.67 \pm 0.81 \mathrm{~b}$ & $78.34 \pm 0.62 \mathrm{a}$ \\
\hline & L3-L4 & $0.64 \pm 0.09 \mathrm{ab}$ & $0.65 \pm 0.02 \mathrm{a}$ & $1.75 \pm 0.16 \mathrm{a}$ & $54.00 \pm 3.31 \mathrm{~b}$ & $55.05 \pm 1.48 \mathrm{a}$ & $147.75 \pm 1.39 \mathrm{a}$ & $19.10 \pm 0.46 \mathrm{ab}$ & $39.42 \pm 0.46 \mathrm{a}$ & $77.55 \pm 1.45 \mathrm{a}$ \\
\hline & L5-L6 & $0.54 \pm 0.12 \mathrm{~b}$ & $0.36 \pm 0.04 \mathrm{~b}$ & $1.83 \pm 0.28 \mathrm{a}$ & $43.95 \pm 4.21 \mathrm{c}$ & $29.55 \pm 2.36 \mathrm{~b}$ & $148.25 \pm 2.36 \mathrm{a}$ & $15.54 \pm 0.50 \mathrm{~b}$ & $21.16 \pm 0.55 b$ & $77.81 \pm 1.82 \mathrm{a}$ \\
\hline \multirow{3}{*}{ Grains } & L1-L2 & $2.44 \pm 0.11 \mathrm{a}$ & $0.91 \pm 0.03 \mathrm{a}$ & $0.33 \pm 0.00 \mathrm{a}$ & $200.10 \pm 5.26 \mathrm{ab}$ & $74.85 \pm 2.36 \mathrm{a}$ & $26.16 \pm 1.46 \mathrm{a}$ & $76.89 \pm 1.24 \mathrm{a}$ & $68.17 \pm 1.31 \mathrm{a}$ & $14.13 \pm 0.42 \mathrm{a}$ \\
\hline & L3-L4 & $2.55 \pm 0.24 \mathrm{a}$ & $0.86 \pm 0.13 \mathrm{a}$ & $0.34 \pm 0.06 \mathrm{a}$ & $204.75 \pm 6.83 \mathrm{a}$ & $68.85 \pm 3.38 \mathrm{ab}$ & $26.54 \pm 2.48 \mathrm{a}$ & $78.67 \pm 1.37 \mathrm{a}$ & $62.70 \pm 1.57 \mathrm{ab}$ & $14.33 \pm 0.53 \mathrm{a}$ \\
\hline & L5-L6 & $2.5 \pm 0.27 \mathrm{a}$ & $0.84 \pm 0.19 \mathrm{a}$ & $0.30 \pm 0.10 \mathrm{a}$ & $195.90 \pm 9.42 b$ & $65.55 \pm 4.21 \mathrm{~b}$ & $23.06 \pm 3.26 \mathrm{a}$ & $75.27 \pm 0.98 \mathrm{a}$ & $59.70 \pm 2.02 b$ & $12.45 \pm 0.60 \mathrm{a}$ \\
\hline
\end{tabular}

\section{Discussion and conclusion}

\subsection{Effects of sprinkling bands on wheat at different line spacing.}


The experiment suggested that the distance from sprinkling band significantly affected the total number of stalks in each community. The number of stalks was higher in L5-L6 than in L3-L4 at anthesis stage and before, but rapidly decreased to the lowest during maturity. The number of spikes was small in L3-L4 at anthesis stage and before, and further reached the minimum level during maturity. The general order of all sampling zones was: L3-L4 $>$ L1-L2 $>$ L5-L6. During the entire experiment, wheat in L1-L2 processed more water and fertilizer, thriving during the early stages with increasing number of invalid cotyledons, resulting in low number of spikes. Short plants appeared in L5-L6 at early stages, and due to the crossing irrigation from two sprinkling bands, the population was bigger. But it became a smaller population at late stages because of the larger size of plants blocking water and fertilizer. Therefore, to eliminate divergence of communities and effectively use water and fertilizer, wheat should be sowed less when it is close to sprinkling. The exact amount of wheat still needs further studies under controlled conditions.

From the inspection during maturity, the yield and plant height of wheat was in following order: L1-L2 $>$ L3-L4 $>$ L5-L6. Grain number per spike and 1000-grain weight were higher in L1-L2 and L3-L4, and lowest in L5-L6. More specifically, spike number was $660.0-706.8 / \mathrm{hm}^{2}$. Grain number per spike was $32.5-34.7$. 1000-grain weight was $31.71-32.53 \mathrm{~g}$ and the yield was $7844.9-8194.8 \mathrm{~kg} / \mathrm{hm}^{2}$. Difference was significant for spike number, but not for grain number per spike, 1000-grain weight and yield, in various zones, indicating the effect of sprinkling on wheat yield was neglectable [10].

\subsection{Effects of divergence of water and nutrient content in soil on wheat nutrient assimilation}

According to the correlation of soil moisture and stage variation of nutrient in soil layers, moisture was positively correlated to the variations of soil nitrogen at different levels in different depth. From heading to filling stage, phosphorus was positively correlated to moisture, while from filling stage to maturity, the correlation was negative. $\mathrm{K}_{2} \mathrm{O}$ was negatively correlated to moisture from filling stage to maturity. For nutrient accumulation and water consumption, $\mathrm{N}$ accumulation and water consumption increased, therefore, stage soil moisture was positively correlated to $\mathrm{N}$ variations to varying degree. Though, $\mathrm{P}_{2} \mathrm{O}_{5}$ accumulation was also highest during maturity, rate of the accumulation was slow at late stages. That is why there was mismatch between soil moisture and phosphorus supply, even negative correlation. $\mathrm{K}_{2} \mathrm{O}$ accumulation was negative at late stages. Especially, significant negative correlation was found between soil moisture and potassium variation in 0-40 cm soil, suggesting the correlation of moisture and nutrient is highly dependent with the assimilation of water and nutrient of wheat at different stages [11]. During farming, $\mathrm{N}$ fertilizer is applied as additional fertilizer at various stages, $\mathrm{P}$ should be added at filling stage and before, and $\mathrm{K}$ should be applied before anthesis. To conclude, with water-fertilizer integration $\mathrm{N}$ and $\mathrm{P}$ fertilizer can be applied as additional fertilization at late stages, while $\mathrm{K}$ fertilizer can be used as base fertilization.

This research showed the order of nutrient accumulation during maturity was: L1-L2 $>$ L3-L4 $>$ L5-L6. But the distribution of nutrient in different organs was irregular, which indicates homogeneity index has no obvious effect on nutrient assimilation and yield of wheat [10]. One of the possible reasons is in this experiment, soil contained sufficient $\mathrm{N}$, P and $\mathrm{K}$ buffering the divergence of nutrients caused by sprinkling irrigation [11,12]. Another reason is probably self-regulation of water and nutrient by roots of wheat eliminated the divergence of water and nutrient in soil. Therefore, controlled experiments are need to investigate water and nutrient consumption under various sprinkling conditions.

\section{Acknowledgments}

This project was supported by: Key Project of Chinese National Programs for Fundamental Research and Development (2018YFD0300505-3); The Key Research and Development Projects in Hebei Province (18227004D-1); Agricultural Science and Technology Innovation Project (2019-4-6-1).

\section{References}

1. Z.L. Li, W.J. Zhao, W Sun, Y.W. Fan, Transactions of the Chinese Society of Agricultural Engineering (Transactions of the CSAE ), 28(2012)

2. S.M. Yao, Y.H. Kang, G.H. Lv, M.J. Liu, W.P. Yang, D.F. Li, Transactions of the Chinese Society of Agricultural Engineering (Transactions of the CSAE), 27(2011)

3. H.G. Wang, D.X. Li, Y.M. Li, R.Q. Li, Agricultural Sciences in China, 48(2015) 
4. L.H. Lv, Q. Li, Z.Q. Dong, Journal of Triticeae Crops, 34(2014)

5. H.K. Dang, Zheng C.L., J.Y. Ma, G.F. Wang, W. Li, K.J. Li, Chinese Journal of Eco-Agriculture, 20(2012)

6. L.P. Yu, G.H. Huang, H.J. Liu, X.P. Wang, D.F. Li, 21(2010)

7. H.Y. Sun, C.M. Liu, X.Y. Zhang, Y.J. Shen, Y.Q. Zhang, Agricultural water management, 85(2006)

8. Y.M. Li, J.P. Zhang, H.Z. Wang, Q.Z. Jiang, J.Y. Wu, H.C. Zheng, Z.B. Geng, Z.M. Peng, Journal of Agricultural University of Hebei, ,25(2002)

9. S.D. Bao, Beijing: China Agriculture Press, 2000(in Chinese)

10. J.S. Li,B. Li, M.S. Su, M.J. Rao, Agricultural Sciences in China, 38(2005)

11. H.K. Dang, R.Q. Li, Y.M. Li, Y.H. Sun, X.W. Zhang, J. Meng, Plant Nutrition and Fertilizing Science, ,19(2013)

12. H.K. Dang, R.Q. Li, Y.M. Li, Y.H. Sun, X.W. Zhang, J. Meng, Plant Nutrition and Fertilizing Science, ,18(2012) 